IP Periodica Polytechnica

Transportation Engineering

45(2), pp. 53-57, 2017

https://doi.org/10.3311/PPtr.9812

Creative Commons Attribution (1)

RESEARCH ARTICLE

\section{Planning and Designing Transport Infrastructures for Sustainability: the Great Project NAPLEST}

\author{
Francesca Pagliara $^{1 *}$, Marialucia Esposito ${ }^{1}$, Claudio Troisi ${ }^{2}$
}

Received 26 July 2016; accepted 24 October 2016

\begin{abstract}
In this paper transport infrastructures are presented highlighting their role in promoting sustainable mobility, i.e. reducing congestion and therefore improving the quality of the environment within which they are conceived. The implementation of the Great Project Naplest in the city of Naples in the south of Italy is here reported as case study. The latter is made up of an integrated set of actions with the objective of overcoming the problems of traffic saturation and therefore of reducing pollutants' emissions in the existing road network with the subsequent renewal of the eastern part of the city itself.
\end{abstract}

\section{Keywords}

transportation planning and design, transport interventions impacts, sustainability, the Great project Naplest

\footnotetext{
${ }^{1}$ Department of Civil, Architectural and Environmental Engineering, University of Naples Federico II

Via Claudio 21 Naples, P.O.B. 80125 Italy

${ }^{2}$ Department of Architecture,

University of Naples Federico II

Via Forno Vecchio 36 Naples, P.O.B. 80125 Italy

*Corresponding author, e-mail: fpagliar@unina.it
}

\section{Introduction}

Transportation systems engineering is a broad discipline aimed at the functional design of physical and/or organizational projects relating to transportation supply systems (Esztergar and Csiszar, 2015). These projects define the functional characteristics and performances of system elements (services, prices, infrastructures, vehicles, control, etc.) that, taken as a whole, provide transportation opportunities to satisfy the travel demand of persons and goods in a given area" (Cascetta, 2009).

Transportation system projects have to be technically feasible and defined on the basis of the quantitative evaluation of their effects with respect to the objectives and constraints of the project itself. Different projects may be proposed. They can include the functional design of new infrastructures; the assessment of long-term investment programs; the evaluation of project financing schemes; the definition of schedules and pricing policies for transportation services; the definition of circulation and regulation schemes for urban road networks; the design of strategies for new advanced traffic control and information systems.

Transport projects may have implications for the economy, the location and intensity of the activities in a given area, the environment, the quality of life and social cohesion.

In the recent book by Cascetta and Pagliara (2015), it is reported that the new transport infrastructures should be LEAN, SMART, GREEN and EYE-FRIENDLY. Concerning the first characteristic, based on the principle and the philosophy of the Lean Production, transport infrastructures should reduce the waste. SMART infrastructures are those using ICT (Information Communication Technologies) technologies for the monitoring and control and for providing information to users. GREEN infrastructure or BLUE-GREEN infrastructure is a network providing information for solving urban and climatic challenges by building with nature. It also serves to provide an ecological framework for social, economic and environmental health of the surroundings. Moreover, today the designer has a more formal freedom, less rules to follow or reference models, historically settled. He/she can combine the technical, economic and aesthetic aspects to create infrastructures which are "EYEFRIENDLY", improving the context in which they are designed. 
A new approach is required to the integrated design, a new design culture, which should be considered at the stage of the interventions planning (at the level of feasibility studies), in which decisions regarding the geometry, the inclusion in the territorial and environmental context, the materials used interact with the computer supports.

All these "ingredients" should be considered for sustainability. Indeed, moving towards a sustainable mobility is the key issue for modern societies, for the transport sector's far reaching effects on economic and social development and the environment. It involves rethinking current transport systems, promoting inter-modality and encouraging the use of the most energy efficient mode of transport for a given transport situation. This is a challenge that requires action and cooperation by all players of society: governments, local authorities, private business, and the individual (Churchman, 2012; EsztergárKiss, Kaderják, Csiszár, 2012)

A concept that is underlined by other authors (Al Waer et al., 2014). Indeed they consider how to approach the design and development of sustainable communities as an integrated process of assessment and planning. The management and operational processes are outlined through which, by a combination of corporate governance and professional team-working, the play of stakeholders can be directed. They propose a sustainability assessment framework to support the provision offeredforward and feed-back intelligence into the planning and development processes.

In this paper the impacts on the road transportation system linked to the implementation of the Great project Naplest in the city of Naples in the south of Italy is presented. This project is made up of an integrated set of actions with the objective of overcoming the problems of congestion in the existing road network with the subsequent renewal of the urban fabric of the eastern part of the city. The paper is organized as follows. The question of transport planning and design transport infrastructures is treated in detail. Then the case study of the Great Project Naplest is presented together with its effects. Finally conclusions and policy implications are described.

\section{The background}

Transportation planning has historically followed the rational planning framework of defining goals and objectives, identifying problems, generating alternatives, evaluating alternatives, and developing plans (Cascetta et al., 2015).

The role of the transport planner, shifting from technical analysis to the promotion of sustainability through integrated transport policies, is becoming more and more common.

A decision process in transportation planning is made up of different macro-activities (see Fig. 1). In the right side of the figure the decision process is reported, while in the left side the phases of analysis and modeling functional to these activities are shown. In the phase of objectives and constraints identification, the objectives of the decision-maker and the relevant constraints for the project are defined (Cascetta, 2009). In the phase of analysis of the present situation, data on the transportation and activity systems are collected. This phase is also linked to the building of a mathematical model of the present system, since it provides the input data for the models (transport supply, transport demand, land-use). From these models, estimates of system performance indicators such as flows, saturation levels, generalized transport costs by Origin-Destination zones of the city can be obtained as a measure of the effects of the interventions on sustaianibility. The formulation of system projects follows. Assessment and evaluation of alternative projects require the simulation of the relevant impacts of their realization.

After the project implementation, forecasted and actual effects can be compared, the occurrence of unexpected developments and new problems can be observed together with the evaluation of social consent and/or dissent. The monitoring of the project is the checking of the main "state variables" of the transportation system and the use of them can identify new problems and the a posteriori evaluation of project impacts.

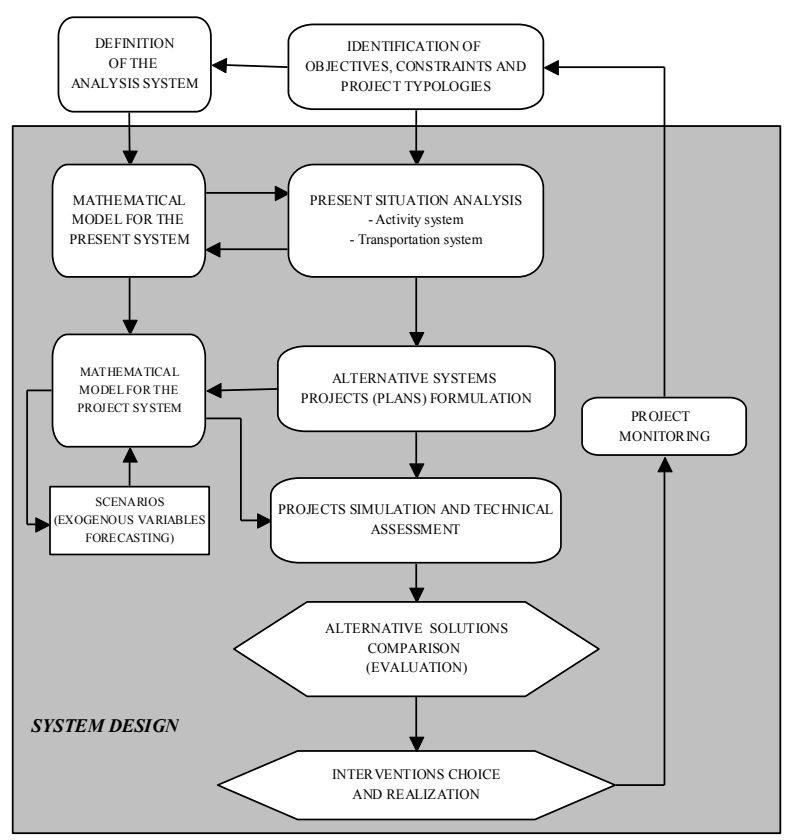

Fig. 1 Transportation systems design and the planning process

The effects of any transport investment can be described in terms of the impacts relevant for some of the actors involved. Thus the definition of the relevant impacts is the main indicator of the approach followed and the breadth of the evaluation activity. The spectrum of the effects considered has widened with the passing of time in concert with improvements in modeling and simulation and with the expansion and classification of the different and often contrasting objectives and goals of actors and decision-makers (Cascetta, 2009). The impacts are considered for all users for the different transportation modes (Pagliara and Papa, 2011). 
Impact indicators are typically computed for a subset of simulation or reference periods and then extrapolated to larger time periods. Many impacts can be simulated by using the models. The estimation of these impacts requires the simulation of the system in the project (P) and non-project (NP) states and the calculation of variations between the variables measuring quantifiable impacts.

Several contributions have been proposed in the literature to quantify impacts.

In the paper by Anas and Tomoru (2012) a spatial computable general equilibrium (CGE) model of the Chicago MSA is specified to analyse how gasoline use, car-VMT, on-the-road fuel intensity, trips and location patterns, housing, labor and product markets respond to a gas price increase. A long-run elasticity of gasoline demand has been found of -0.081 , keeping constant car prices and the TFI (technological fuel intensity) of car types but allowing consumers to choose from car types. $43 \%$ of this elasticity switches to transit; $15 \%$ from trip, car-type and location choice; 38\% from price, wage and rent equilibration, and $4 \%$ from building stock changes.

In the contribution by Liu et al. (2012), an attempt has been made to reveal intra-urban land use variations from traffic patterns. Using a seven-day taxi trajectory data set collected in Shanghai, authors have investigated the temporal changes of both pick-ups and drop-offs, and their association with different land use features. The study shows that human mobility data from location aware devices represent an opportunity to derive urban land use information in a timely fashion, and help urban planners and policy makers in mitigating traffic, planning for public services and resources, and other purposes.

The road safety characteristic of foreign traffic arriving from the Visegrad Countries to Hungary has been investigated in the paper by Török (2014). The principle is to support and harmonise the coordination of preparations and implementation of national road traffic safety programmes involving the most appreciated specialists of the discussed professional field. A key factor for the safety of road transport is the infrastructure design.

\section{The case study}

Campania region is one of the twenty administrative regions making up Italy. It has about 5.7 million inhabitants and is the second largest region in Italy (Pagliara et al., 2015). It is made up of five administrative provinces and the large central metropolitan area is centred around Naples with 3.5 million inhabitants. During the second half of the last century, very limited investments were made to expand and/or upgrade the existing network. Furthermore, these efforts followed an un-coordinated process in which decisions were taken by individual transport companies, thereby limiting an integrated vision of the regional railway system. Moreover, expansion projects were not coordinated with decisions involving the land-use system. Indeed they were often made independently of the system. In 1996 the new planning approach started and it was extended in 2001 to the whole region with the Regional Metro System (RMS) project, which is based on the principle that only an extended railway system can guarantee a sustainable mobility in this area (Cascetta and Pagliara, 2008).

In the last years several interventions have been carried out on the urban rail network with the opening of new rail lines and of many stations both in the central and peripheral areas of the city of Naples (Cascetta et al., 2011).

Several interventions on road network have been considered as well. In Fig. 2 the area of the city of Naples interested by the Great Project Naples.

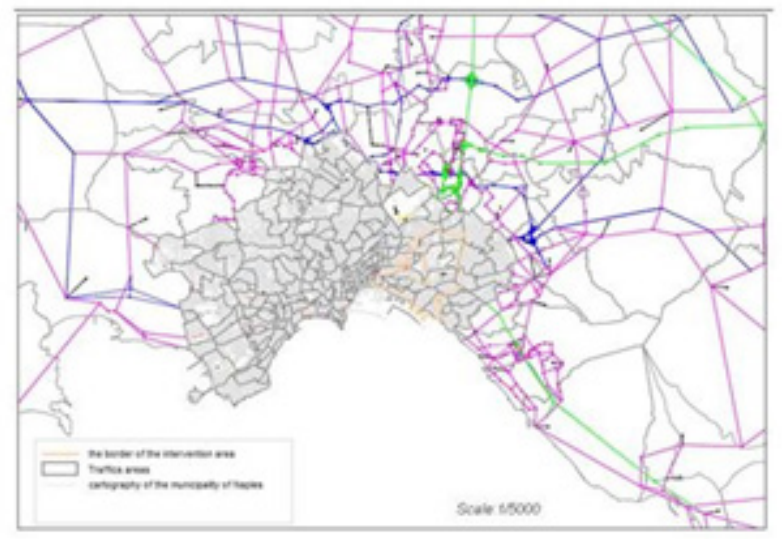

Fig. 2 The city of Naples and the study area highlighted in blue; Source: Authors, elaboration

In Fig. 3 the current scenario is presented (road network links + nodes).

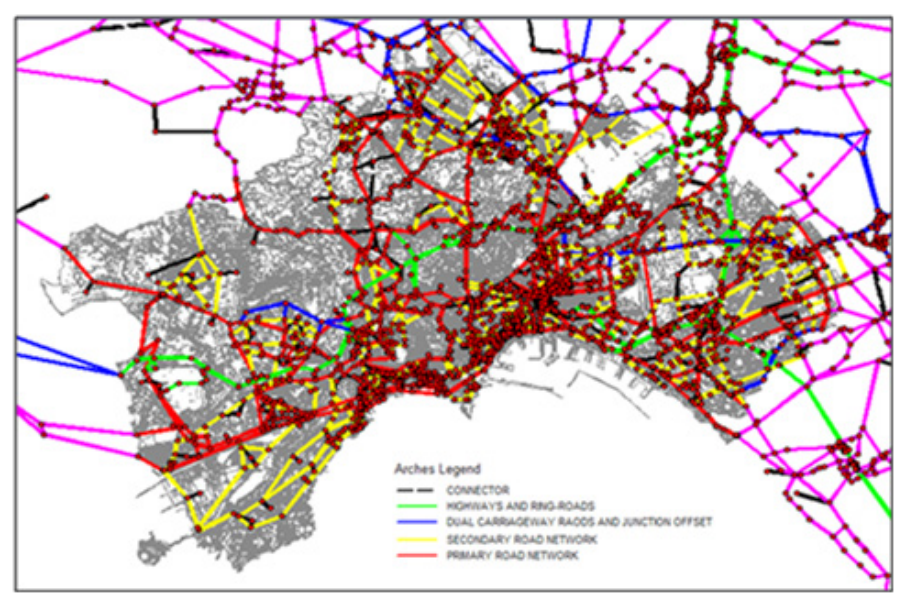

Fig. 3 Current scenario

The project scenario, i.e. the interventions of the Great Project Naplest, is reported in Fig. 4. 


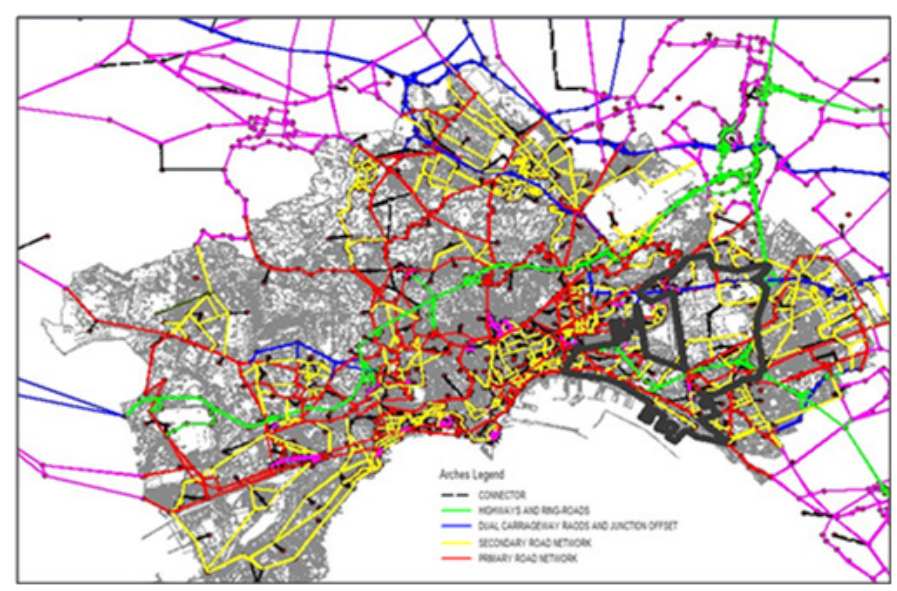

Fig. 4 Naplest scenario (road network: links + nodes)

The first step has been that of the transport demand analysis in the area under study, based on the random utility theory (Cascetta, 2009). Then it follows the simulation of the current system scenario and that of the Naplest scenario. The last step has been the evaluation of the performance indicators for both scenarios and their comparison, according to the framework reported in Fig. 1. The travel demand has been estimated using traffic counts obtained in four sections of the study area close to Garibaldi's square.

The traffic counts were conducted between 7.00 am -10.00 am on Thursday, May 7th 2015, considered as an average weekday.

The flows were calculated by classifying them in categories of vehicles (i.e. cars, commercial vehicles, heavy vehicles, motorcycles, and buses) and then transformed into equivalent vehicles with the appropriate factors of equivalence.

\section{Results and Discussion}

The flows of the current scenario (see Fig. 5) and the flows of the Naplest scenario (see Fig. 6) have been obtained, using the simulation software MT Model. The flows are expressed in terms of equivalent vehicles/h during the peak period in the morning.

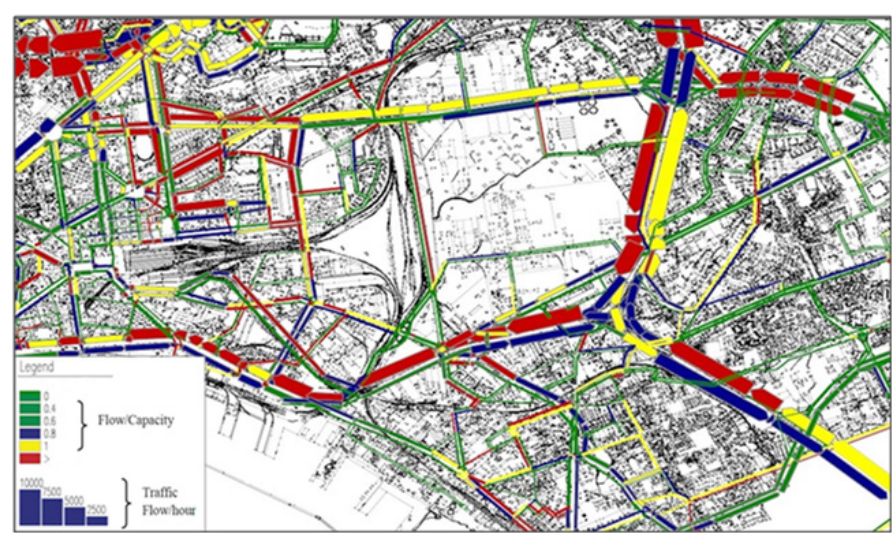

Fig. 5 Flows for the current scenario (Mt Model software results)

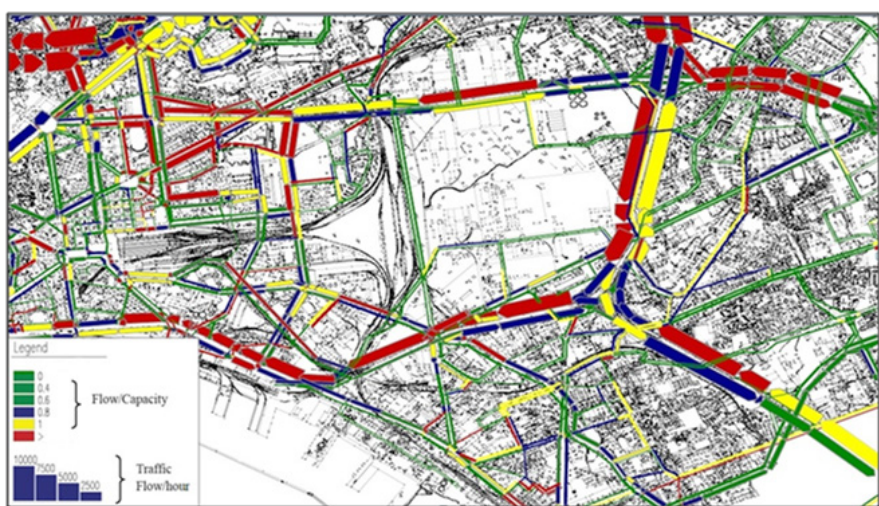

Fig. 6 Flows for scenario Naplest (Mt Model software results)

The simulation of the current scenario shows that there are high levels of congestion in many points with values of flow/ capacity above 1 (yellow links).

Comparing the flows of the two scenarios, it is possible to see how the situation improves in the Naplest scenario. Indeed a reduction of congestion is registered.

The impacts of the Great Project Naples have been estimated in terms of changes of the network performances and accessibility indicators between the current scenario and the Naplest scenario, reported in Table 1.

Table 1 Performance and accessibility indicators PERFORMANCE INDICATORS

Vehicles-Km $=\sum_{l} L l * h l$

Vehicles- $\mathrm{h}=\sum_{l} T l * h l$

Average speed on the network $(\mathrm{Km} / \mathrm{h})=\sum_{l} L l * h l / \sum_{l} T l * h l$

$T l$ and $L l$ are the travel times in minutes and the length of link of the network in kilometers respectively

The results obtained are presented in Tables 2 and 3.

Table 2 Performance indicators for the current scenario INDICATORS OF PERFORMANCE FOR THE CURRENT SCENARIO (Naplest area)

\begin{tabular}{cc}
\hline Vehicles-Km & 117878 \\
Vehicles- $\mathrm{h}$ & 14677 \\
Average speed on the network $(\mathrm{km} / \mathrm{h})$ & 8.03 \\
\hline
\end{tabular}

Table 3 Performance indicators for the scenario Naplest

INDICATORS OF PERFORMANCE FOR THE NAPLEST SCENARIO (Naplest area)

$\begin{array}{lc}\text { Vehicles-Km } & 118219 \\ \text { Vehicles- h } & 13190\end{array}$

Average speed on network $(\mathrm{Km} / \mathrm{h})$ 8.96

Based on the results obtained, it is possible to say that the intervention proposed by the "Great project Naplest", have led to an improvement of the performance of the network. There is an increase of the average speed on the network, obtained with an increase of vehicles-Km and a reduction in terms of vehicles $/ \mathrm{h}$. 
Moreover an improvement of accessibility of the eastern areas of Naples is registered with a reduction of the travel time and the distance for the users of the road transportation system.

\section{Conclusions and policy implications}

Urban systems are complex systems governed by many degrees of freedom, interacting on different space and time scales. Their evolution is shaped by internal factors, such as decisions taken by institutions and individuals and external causes (international economic context), and by social development (Cascetta et al., 2007).

Transportation systems are strategic in this context since they are a tool of social cohesion and they are a powerful element in promoting economic and employment development and establishing an equilibrium between territorial areas with different levels of accessibility.

The number of travellers or goods using these physical elements (i.e. roads) and, through congestion, their performances and impacts are strictly connected with travel demand and users' behaviour. Thus the analysis of travel demand plays a key role in understanding and designing transportation systems.

The Great Project Naplest is a clear example of positive impacts on urban renewal in an area of the city of Naples, almost abandoned. Indeed the proposal of integrated land-use/ transport policies have turned out to appropriate for reducing congestion and improving urban and mobility sustainability. Promoting investments in transport infrastructures and, integrating networks and services improve both qualitatively and quantitatively the public transport, with a subsequent increase of its use. There follow a reduction in the use of cars, a reduction in the air pollution and noise, and better living conditions. An example of the virtuous cycle of mobility in urban systems, reported in Fig. 7, should be considered in any decision-making process aiming at sustainability.

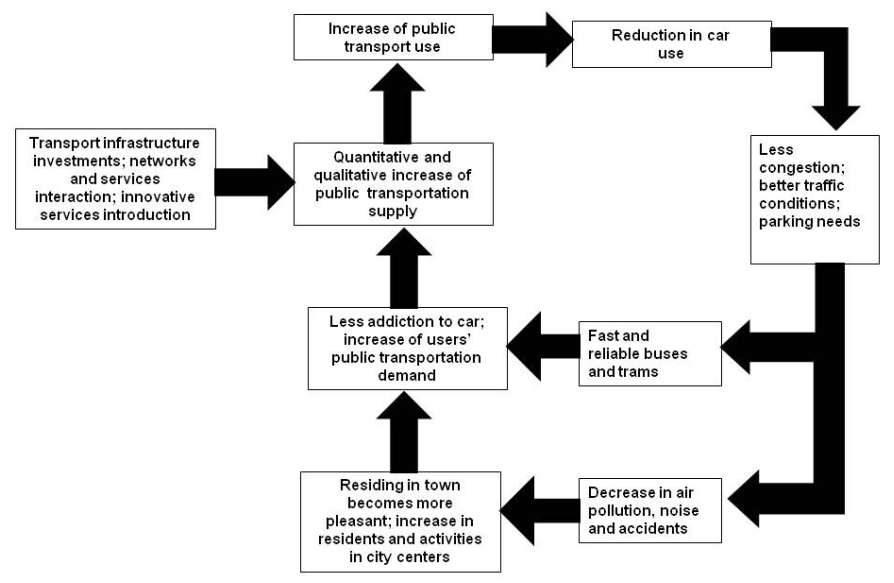

Fig. 7 The virtuous cycle of mobility Source: Cascetta et al. (2007)

\section{References}

Al Waer, H., Bickerton, R., Kirh, D. (2014). Examining the components required for assessing the sustainability of communites in the UK. Journal of Architectural and Planning Research. 31(1), pp. 1-36.

Anas, A., Hiramatsu, T. (2012). The effect of the price of gasoline on the urban economy: From route choice to general equilibrium. Transportation Research Part A: Policy and Practice. 46(6), pp. 855-873. https://doi.org/10.1016/j.tra.2012.02.010

Cascetta, E. (2009). Transportation systems analysis. Models and applications. 347 p. Springer, New York. https://doi.org/10.1007/978-0-387-75857-2

Cascetta, E., Cartenì, A., Pagliara, F., Montanino, M. (2015). A new look at planning and designing transportation systems: A decision-making model based on cognitive rationality, stakeholder engagement and quantitative methods. Transport Policy. 38, pp. 27-39. https://doi.org/10.1016/j.tranpol.2014.11.005

Cascetta, E., Pagliara, F. (2008). Integrated railways-based policies: The Regional Metro System (RMS) project of Naples and Campania. Transport Policy. 15(2), pp. 81-93. https://doi.org/10.1016/j.tranpol.2007.11.001

Cascetta, E., Pagliara, F. (2015). Le infrastrutture di trasporto in Italia: cosa non ha funzionato e come porvi rimedio. (Transport infrastructures in Italy: what has not worked and how to solve it.) 288 p. Aracne, Rome. (in Italian)

Cascetta, E., Papola, A., Pagliara, F., Marzano, V. (2011). Analysis of mobility impacts of the high speed Rome-Naples rail link using within day dynamic mode service choice models. Journal of Transport Geography. 19(4), pp. 635-643. https://doi.org/10.1016/j.jtrangeo.2010.07.001

Churchman, A. (2012). Public participation around the world: introduction to the special issue. Journal of Architectural and Planning Research. 29(1), pp. 1-4.

Esztergár-Kiss, D., Csiszár, Cs. (2015). Evaluation of Multimodal Journey Planners and Definition of Service Levels. International Journal of Intelligent Transportation Systems Research. 13(3), pp. 154-165. https://doi.org/10.1007/s13177-014-0093-0

Esztergár-Kiss, D., Kaderják, P., Csiszár, Cs. (2012). Elaboration of a Method's Theory regarding the Establishment and Revision of Bus Lanes. Acta Technica Jaurinensis. 5(3), pp. 271-282.

Liu, Y., Wang, F., Xiao, Y., Gao, S. (2012). Urban land uses and traffic 'sourcesink areas': Evidence from GPS-enabled taxi data in Shanghai. Landscape and Urban Planning. 106 (1), pp. 73-87.

https://doi.org/10.1016/j.landurbplan.2012.02.012

Pagliara, F., Papa, E. (2011). Urban rail systems investments: an analysis of the impacts on property values and residents' location. Journal of Transport Geography. 19(2), pp. 200-2011.

https://doi.org/10.1016/j.jtrangeo.2010.02.006

Pagliara, F., Troisi, C., Pelliccia, L. (2015). A before and after analysis of the impacts of the inauguration of a new metro station in Naples. The Open Transportation Journal. 9, pp. 1-8.

Török, Á. (2014). Safety analysis of foreign traffic from Visegrad Countries on the Hungarian network. Periodica Polytechnica Transportation Engineering. 42(2), pp. 153-157. https://doi.org/10.3311/PPtr.7218 